\title{
Special Issue on Applications of Radioactive Geochemistry in Earth Sciences \\ Preface
}

The 9th International Conference on Gas Geochemistry (ICGG9) was held in Taipei, Taiwan 1-8 October, 2007 (Yang, 2008; Yang et al., 2009, 2010). This conference was a sequel to the last two meetings held in Freiberg, Germany, in 2003 (Heinicke and Martinelli, 2005; Yang et al., 2005a, b), and Sicily, Italy, in 2005 (Boschi et al., 2007; Italiano et al., 2007), consequently in Cluj-Napoca, Romania in 2009 (Etiope and Baciu, 2010). The next conference will be held in La Jolla, USA in 2011. The conference was devoted to all aspects of research and development on gas geochemistry and its applications in earth and planetary sciences. We had brought together the leading researchers in the field of gas geochemistry to share their most recent experiences, advances and upgrading in analytical techniques and in theoretical modeling to achieve a better understanding of the special role of gases in different processes and systems of Earth.

A total of 105 abstracts were presented by 129 registered scientists from 23 countries in the conference. They covered all kinds of recent applications of gas geochemistry in the field of earth/environmental sciences. Among them, radioactive geochemistry, especially Radon gas, which is a very unique tracer for physics processes due to its rarity on Earth and to its inertness. It has been widely used for long-term surveillance on the magma activity in volcanic/hydrothermal areas and earthquake activity in earthquake-prone areas, especially at fault zones. Because of its radioactivity, emission of radioactive gases in natural environments and also indoors, radon is a potential hazard for human beings in some areas; therefore, it is important to understand the background level of emission flux and to monitor the radioactivity in living environments for some areas.

Many recent works of the above mentioned applications have been presented in the ICGG9. Therefore, we consider it a good time to publish a special issue to show readers the recent applications of radioactive geochemistry in earth sciences. We also invited colleagues who did not participant at the conference but have been working in this field for years to contribute their experiences and recent works. After peer review, eleven contributions have been selected for this special issue.

The first contribution of this issue, Mehra et al. measured the radioactivity of soil samples to assess the aver-

Copyright @ 2011 by The Geochemical Society of Japan. age effective dose from ${ }^{226} \mathrm{Ra},{ }^{232} \mathrm{Th}$ and ${ }^{40} \mathrm{~K}$ in Punjab, India and concluded that soil from these regions is safe and can be used as a construction material without posing any significant radiological threat to population. Vaupotic et al. report relatively low tritium concentrations of springs samples from Slovenia, except for few samples that may be contaminated by the tritium discharge from nuclear power plant and suggest that tritium data can provide an indication of the spring water recharge in the area. Kies et al. found that radon concentrations in glacier meltwater are surprisingly high and thus could be used as valuable tracer for the glacier drainage system and its evolution over time. Mysocka measured radon activity in some Jurassic caves of Poland and found that the radon exposure to speleologists can be comparable or even higher than that of underground miners. She suggested that it is important to inform the speleologists to minimise the time of underground stays to reduce the potential radiation risk. Solecki and TchorzTrzeciakiewicz carefully measured the radon exhalation from the coal ash and concluded that radon can be released from a very thin external layer of fine grained coal ash material. The released radon amount could be comparable with that from huge tailings of analogous material. Yang et al. measured the soil radon concentrations and $\mathrm{CO}_{2}$ flux in situ in a geothermal area of northern Taiwan. They found that both $\mathrm{CO}_{2}$ flux and radon concentrations show significant variations and are correlated well with other sensitive magmatic proxies, therefore, they may be useful for further monitoring for the local magma activity.

The second part of this issue is mainly the result of continuous long-term observation of radon data in different areas. Chyi et al. report observed spike-like anomalies of soil radon at active fault zones. Based on laboratory experiment and field observation, they proposed that radon release from a fault zone is sensitive to electrokinetic or self-potential phenomena related to crustal stress but significant amount of radon could come from deeper source, and therefore, might be able to estimate the magnitude and time of an upcoming earthquake from the observed spike-like radon anomalies. Laskar et al. also present continuous soil radon data in the Guwahati city, Assam, India. Applying the multiple regression method, the authors derived an equation to remove the influences of ambient temperature, atmospheric air pressure and relative humidity on the temporal variation of 
soil radon concentration, and then radon anomaly peaks can be selected accordingly to further correlate the possible link between the anomalies and observed earthquakes. Woith et al. continuously monitored the radon concentration in a Roman spring of Tiberias, Israel from 2000 to 2005 . From the long-term monitoring results they found a transient drop of radon level in 2003. The authors suspect that it is physically linked to the lake level variation at a nearby border fault. They further concluded that radon could be a powerful proxy to monitor pressure changes within a fault system. Montazeri et al. also report the continuous monitoring result of dissolved radon in the Jowshan hot spring, SE Iran. The authors asserted that anomalies of radon concentration in spring water can be observed before some earthquake events, although they admit that more continuous monitoring data of water chemistry in addition to radon data are necessary to verify the precursory anomalies. The last paper of this issue, Tchorz-Trzeciakiewicz and Soleck continuously monitored the atmospheric radon concentrations from 2004 to 2007 in an abandoned coal mining area of southwest Poland. They found that the air radon level is strongly controlled by the uranium content of local basement; meanwhile, temperature and humidity are also important factors to affect the seasonal variations and could induce the higher air radon activity in the summer time of the monitoring period.

The guest editors would like to thank all authors who have contributed to this special issue. We are also grateful to all reviewers for providing critical and constructive comments/suggestions that improved the manuscripts. Editor-in-chief Professor Yuji Sano of the journal is thanked for supporting this special issue. Without their efforts the publication of this special issue would not be possible.

Boschi, E., Italiano, F. and Martinelli, G. (2007) Preface: Fluids and tectonics. Ann. Geophys. 50(4), V-IX.
Etiope, G. and Baciu, C. (2010) Geofluids and natural gas in Romania, and the 10th International Conference on Gas Geochemistry. Geofluids 10, 457-462.

Heinicke, J. and Martinelli, G. (2005) Preface: an historical overview of gas geochemistry. Ann. Geophys. 48(1), V-VIII.

Italiano, F., D'Alessandro, W. and Martelli, M. (2007) Gas geochemistry as a tool to investigate the Earth's degassing through volcanic and seismic areas: The soul of the 8th International Conference on Gas Geochemistry. J. Volcano. Geotherm. Res. 165, 1-4.

Yang, T. F. (2008) Recent progress in the application of gas geochemistry: examples from Taiwan and the 9th International Gas Geochemistry Conference. Geofluids 8, 219-229.

Yang, T. F., Chen, C.-H. and Liu, T. K. (2005a) Preface to the special issue on Geochemical Investigations on the Geohazards. Terr. Atmos. Ocean. Sci. 16(4), I-VI.

Yang, T. F., Italiano, F. and Heinicke, J. (2005b) Special issue on recent progress in gas geochemistry-Preface. Geochem. J. 39, 395.

Yang, T. F., Marty, B., Hilton, D. R. and Kurz, M. D. (2009) Geochemical applications of noble gases. Chem. Geol. 266, $1-3$.

Yang, T. F., Hilton, D. R., Italiano, F. and Heinicke, J. (2010) Applications of fluid and gas Geochemistry on geohazards investigation. Appl. Geochem. 25, 503-504.

\section{Guest Editors}

Tsanyao Frank Yang

Department of Geosciences, National Taiwan University, Taipei 106, Taiwan

(e-mail: tyyang@ntu.edu.tw)

L. Lynn Chyi

Department of Geology and Environmental Science, University of Akron, Akron, OH 44325-4101, U.S.A. (e-mail: lchyi@uakron.edu)

Surinder Singh

Department of Physics, Guru Nanak Dev University, Amritsar - 143005, India

(e-mail: surinder_s1951@yahoo.co.in) 